\title{
Adherence to Quarantine Protocols to Prevent the Spread of COVID-19: The Moderating Effect of Social Media Campaigns
}

\author{
Nelson B. Guillen Jr. \\ Marketing and Advertising Department, De La Salle University, Manila, Philippines \\ Email: nelson.guillen@dlsu.edu.ph
}

How to cite this paper: Guillen Jr., N. B. (2021). Adherence to Quarantine Protocols to Prevent the Spread of COVID-19: The Moderating Effect of Social Media Campaigns. Advances in Journalism and Communication, 9, 85-101.

https://doi.org/10.4236/ajc.2021.93007

Received: June 16, 2021

Accepted: August 13, 2021

Published: August 16, 2021

Copyright $\odot 2021$ by author(s) and Scientific Research Publishing Inc. This work is licensed under the Creative Commons Attribution International License (CC BY 4.0).

http://creativecommons.org/licenses/by/4.0/

\section{Open Access}

\begin{abstract}
This study focuses on Metro Manila in the Philippines in preventing the spread of the novel coronavirus or COVID-19 through analyzing the moderating effect of social media campaigns on adherence to COVID-19 protocols. Metro Manila is the pandemic's epicenter with a strict implementation of quarantine protocols set by the Local Government Units (LGUs). This study also examines the factors that influenced Metro Manila residents to adhere to quarantine measures. Four hundred thirteen residents (413) joined the survey consisting of sixteen (16) cities and one (1) municipality in Metro Manila. Using the Theory of Planned Behavior, the direct relationships between attitude, controllability, social media and adherence to quarantine protocols were significant. This implies that social media has directly influenced adherence to quarantine protocols. However, social media did not moderate the relationship between subjective norm and self-efficacy in the adherence to quarantine protocols. The relationship between subjective norm and self-efficacy in adherence to quarantine protocols was not significant either. It was not others such as family and peers who encouraged the resident to adhere, but it was his or her decision to survive and stay alive. Finally, the study shows the crucial role of social media in helping minimize the spread of COVID-19.
\end{abstract}

\section{Keywords}

COVID-19, Quarantine Protocols, Prevention, Theory of Planned Behavior, Social Media

\section{Introduction}

The World Health Organization declared COVID-19 as a pandemic last March 
11, 2020. Various media organizations, both online and offline, have allowed the public to recognize the seriousness of COVID-19 (Vallejo \& Ong, 2020). According to CNN, COVID-19 infected 168 million people worldwide and claimed almost 4 million lives as of May 26, 2021 (CNN Health, 2021). This CNN report showed that there were 1.19 million COVID-19 cases and 20,019 deaths in the Philippines as of May 26, 2021. Governments worldwide, including the Philippine government, vigorously enforced physical distancing, area-wide lockdowns and curfews, and contact tracing of persons under investigation (Biana \& Joaquin, 2020). According to Biana and Joaquin (2020), the government widely used digital tools such as social media in the form of infographics and hashtags to encourage people to adhere to quarantine protocols.

In the Philippines, the Enhanced Community Quarantine (ECQ) was announced on March 13, 2020, and was initially limited to the National Capital Region (NCR) but was expanded to nearby provinces as more cases of local transmission were recorded (Vallejo \& Ong, 2020). Under the ECQ, all modes of travel were suspended (Prasetyo et al., 2020). To prevent the threat of the spread of COVID-19, the residents, through social media, particularly Facebook, were told to stay at home and go out only to buy essential goods (Prasetyo et al., 2020). Other quarantine protocols from the Department of Health in the Philippines, which were aired live on TV and social media, included the following: frequent handwashing, social distancing, covering nose and mouth when coughing, not touching the face, staying at home if unwell, seeking medical attention in case of fever, cough and difficult breathing (Torneo et al., 2020). The adherence to quarantine protocols of Metro Manila residents was criticized on social media because some LGUs could not enforce strict quarantine protocols.

Although the role of the LGU is crucial to quarantine adherence, there are very few studies on the role of social media to encourage quarantine adherence, especially in the Philippines. In a crisis like COVID-19, the public depends on social media for timely and informed decisions, such as following quarantine protocols (Garfin et al., 2020). People nowadays are more vigilant in verifying fake news. According to Garfin et al. (2020), traditional media (TV, radio and newspaper) and new media (Facebook, YouTube, Twitter and Instagram) can provide information that can encourage the public to engage in health behaviors to prevent the spread of COVID-19. This study aims to determine and answer the research question regarding the influence of social media campaigns on Metro Manila residents' adherence to quarantine protocols.

\section{Literature Review}

The literature review section was organized into ten (10) main sections which describe the: 1) Theory of Planned Behavior; 2) Attitude Towards the Behavior and Adherence to Quarantine Protocols; 3) Subjective Norm and Adherence to Quarantine Protocols; 4) Perceived Behavioral Control and Adherence to Health Behaviors; 5) Social Media and Adherence to Quarantine Protocols; 6) Social 
Media and its Engagement; 7) The Changing Social Media; 8) Attitude, Media, and Adherence to Quarantine Protocols; 9) Subjective Norms, Media, Adherence to Quarantine Protocols; and 10) Perceived Behavioral Control, Media, and Adherence to Quarantine Protocols. Following the literature review section, the conceptual framework and hypotheses development section will be proposed.

\subsection{Theory of Planned Behavior}

The Theory of Planned Behavior (TPB), as shown in Figure 1, has three socio-cognitive variables, namely attitude towards the behavior, subjective norm, and perceived behavioral control, which independently affect a person's intention to behave in a specific manner (Ajzen, 2006). According to Ajzen (2006), behavioral intention is the most proximal predictor of human behavior.

Attitude towards the behavior is the individual's positive or negative belief about performing a specific behavior. On the other hand, the subjective norm is the subjective pressure to perform or not perform that behavior. This is influenced by normative beliefs, which according to Ajzen (2006), was influenced by the approval or disapproval of family, friends, and partners towards performing the behavior, including the motivation of the person to comply with pressure. Perceived behavioral control is the perception of ease or difficulty in performing the specific behavior, influenced by control beliefs. This includes the concepts of self-efficacy and the controllability of performing the specific behavior (Ajzen, 2006). In TPB, perceived behavioral control and intention, taken together, can predict the performance of the behavior. An increase in perceived behavioral control while keeping the intention level constant will bring about the performance of the specific behavior (Ajzen, 2006).

\subsection{Attitude towards the Behavior and Adherence to Quarantine Protocols}

Attitude towards adherence to quarantine protocols can encourage a resident to comply with the protocols. Residents who have a positive attitude towards adherence to protocol quarantines will follow it. A study of 649 Filipinos in the NCR showed that a favorable attitude towards quarantine protocols positively affected the intention to follow COVID-19 prevention measures (Prasetyo et al., 2020).

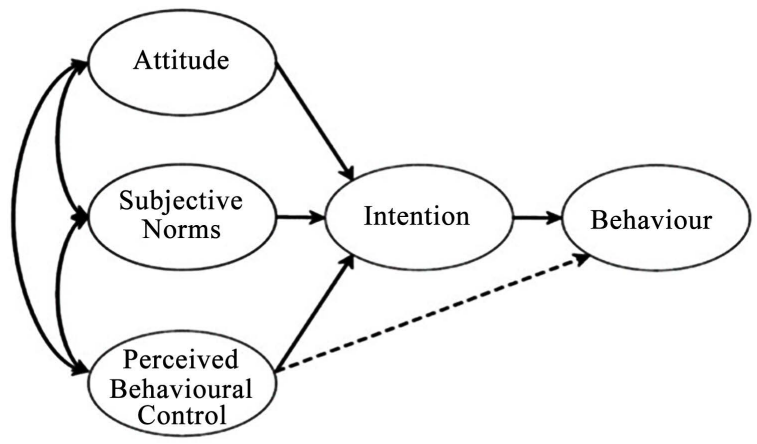

Figure 1. The theory of planned behavior (Ajzen, 2006). 
Omodior et al. (2015) researched to determine the intention to engage in personal protective behaviors against tick-borne diseases among visitors in an outdoor recreational center. They identified six dependent variables, namely 1) Wearing pants, sleeved-shirts, or light-colored clothing; 2) Tuck shirts and pants into socks; 3) Use tick repellent on skin or clothing; 4) Regularly check for ticks on clothes and body; 5) Refrain from staying in wooded or grassy areas; and 6) Choose to walk the center of the trails. The attitude was a significant predictor for most variables, including the overall intention to engage in preventive behaviors.

\subsection{Subjective Norm and Adherence to Quarantine Protocols}

Subjective norms such as family, friends, and partners can also motivate a resident to comply with the health behavior. Mo et al. (2019) found that women engaged in compensated dating had a higher intention for future HIV testing when their peers were supportive of the behavior. Ay et al. (2019) showed that the subjective norm of healthcare workers towards hand hygiene was influenced by social cohesiveness and a sense of belongingness with the Intensive Care Unit team. White et al. (2015) found that Australian nurses reported that their colleagues influenced their normative beliefs towards hand hygiene the most. Superiors, patients, and representatives from infection control also built their normative beliefs and their own families, as they could risk infecting them with poor sanitary practices (White et al., 2015). A study on Filipinos in NCR showed that normative influence or action being done by others would likely attract others to follow or replicate the same action (Prasetyo et al., 2020).

\subsection{Perceived Behavioral Control and Adherence to Health Behaviors}

Self-efficacy and controllability, which are concepts under perceived behavioral control, can influence adherence to quarantine protocols. Self-efficacy refers to a resident's general capability to adhere to quarantine protocols, while controllability refers to the facilitating conditions such as financial or social conditions that can assist in complying with quarantine protocols (Ajzen, 2006). The study on factors influencing Filipinos to adhere to health behaviors to prevent the spread of COVID-19 in NCR showed that Filipinos with greater self-efficacy and controllability are most likely to stay at home and comply with the lockdown implementation of the country, city, and community (Prasetyo et al., 2020).

\subsection{Social Media and Adherence to Quarantine Protocols}

Ajzen (2006) pointed out that the TPB can also include other constructs aside from attitude, subjective norm, and perceived behavioral control (self-efficacy and controllability). This study extends the existing framework by including social media as a moderating variable. The study on panic analysis during the COVID-19 pandemic in the Philippines showed that correct information dissemination was needed to prevent panic behavior (Nicomedes \& Avila, 2020). This implies that 
social media has a crucial role in encouraging preventive health behaviors, especially during quarantine. According to Garfin et al. (2020), social media has a crucial role to play as public health officials, scientists, and journalists need critical information to advise the public on appropriate precautions to minimize the spread of COVID-19. Furthermore, social media with appropriate and responsible information can influence the public to engage in appropriate health-protective behaviors to minimize the spread of COVID-19 (Garfin et al., 2020). Garfin et al. (2020) also cautioned that the type and amount of social media exposure could also lead to stress in times of pandemic. According to the authors, responsible social media messages needed in times of pandemics to promote healthy behavior should not include sensationalism or disturbing messages (Garfin et al., 2020). Medical professionals, including psychologists and psychiatrists, and scientists, should convey credible messages to encourage residents to comply with quarantine protocols (Bilal et al., 2020; Lep et al., 2020).

\subsection{Social Media and Its Engagement}

Content is the driving force to attract, engage, and delight customers. It engages people with a compelling brand message (Kotler \& Keller, 2018). Facebook is not just a network to gain more friends. It is a platform to build engagement, whether for personal or business purposes. The capability to reply to react, share, comment, and click hashtags was designed to keep Facebook users on track to discover timely and relevant content (Kotler \& Keller, 2018). Engagement on specific content is not just about capturing attention; it also measures how many people like, share, and follow posts. A post becomes viral when more and more people like and share it because it is authentic (Kotler \& Keller, 2018). Facebook engagement is about the type of people who sees a post; Facebook's algorithm determines what story will appear on the news feed with the help of Insights, giving information in terms of reach, whether organic or paid. Engagement can also describe the typical audience. "The volume of engagement a specific content receives can indicate the quality of your audiences, and engagement on certain types of posts can provide insight about what they are interested in (Kotler \& Keller, 2018).”

\subsection{The Changing Social Media}

The Philippines has been very active on social media, particularly Facebook. Filipinos spent an average of 4 hours and 17 minutes per day on Facebook, Instagram, and Twitter. The country's social media usage is increasing despite intermittent internet connectivity. Internet speed in the country is among the slowest in Asia and the Pacific (Hlavac, 2017). Marketers are faced with challenges in an evolving digital landscape. Given this pandemic, marketers are compelled to put resources toward digital and social efforts to maintain current returns.

Today's social media and integrated marketing communications specialists are forcing digital transformation to cope with disruption. Bilal et al. (2020) have 
stressed that new media is a powerful tool today, a platform that can disseminate information to provide some relief from panic and boost the morale of the public during COVID-19. The researcher suggested that medical practitioners should have social media campaigns to encourage the public to engage in health behaviors. Furthermore, YouTube or Facebook videos featuring residents who have recovered from COVID-19 and complimenting medical front-liners for their valiant services should be aired.

\subsection{Attitude, Media, and Adherence to Quarantine Protocols}

Lovejoy et al. (2015) found that exposure to health media like television and social media was positively related to avoidance of unprotected exposure to the sun, which may lead to the development of skin cancer. This was consistent with earlier studies that suggest that a positive attitude towards health behaviors can be due to health media exposure. Additionally, Lovejoy et al. (2015) found that individuals who had higher exposure and an encouraging attitude to health information across various health media channels, whether online or offline, avoided unprotected sun exposure. Similarly, Stryker et al. (2008) found that particular to health media use and skin cancer protection behavior, individuals who reported positive attitudes to health news in newspapers had more knowledge about skin protection and engagement in health prevention behavior. This implies that social media can influence the attitude of Metro Manila residents towards adherence to quarantine protocols.

\subsection{Subjective Norms, Media, and Adherence to Quarantine Protocols}

Namkoong et al. (2017) found that an interactive health communication campaign against smoking over social networking sites like Facebook and Twitter increased the use of these channels for the information-seeking behavior of individuals, and consequently changed their attitudes and perceived social norms towards smoking, which ultimately affected their intention to reduce the behavior. The treatment group demonstrated that concerning the campaign, the use of the internet was not passive media consumption, but rather deliberate and involved both cognitive elaboration and collective consideration (Namkoong et al., 2017). Moreover, Namkoong et al. (2017) suggested that the World Wide Web might be a more effective channel for gaining relevant information and sharing ideas and opinions versus traditional modes of mass media like television, print, and word of mouth communications. According to Duggan and Street (2015), social media campaigns can be cost-effective as the number of individuals with social network accounts is continuously increasing. Moreover, Boyd and Ellison (2008) find that social media had already been integrated with the lives of young individuals whom their peers can influence to engage in healthier behaviors. Namkoong et al. (2017) suggest that interactive campaigns over social media can be beneficial for various community-related issues such as public health. This can include smoking, nutrition, socio-civic behaviors like donation drives, 
fundraising and volunteerism, and environmental concerns like recycling. This implies that social media can strengthen the relationship between subjective norms and adherence to quarantine protocols.

\subsection{Perceived Behavioral Control, Media, and Adherence to Quarantine Protocols}

Sundstrom et al. (2018) developed 'It is Your Place,' a theory-based multimedia health communication campaign to prevent sexual assault on campus, and found that exposure to this had a significant effect on self-efficacy and controllability of bystanders towards the intention to intervene to prevent a sexual assault from happening. After seeing the campaign, participants of the study reported that they had a more positive attitude towards bystander intervention, a greater sense that the important people around them would expect them to intervene, and that they were equipped with more knowledge and skills to prevent a sexual assault occurrence (Sundstrom et al., 2018). LaBelle et al. (2020) developed 'Rethink,' a health communication campaign to reduce the normalization of prescription stimulant misuse on college campuses for performance enhancement during periods of high academic stress. The campaign, which used traditional media, print, social media, events, and promotional items, aimed to inform college students of the health risks and legal consequences of misusing prescription stimulants like Adderall, Ritalin, and Concerta (LaBelle et al., 2020). It was found that the campaign was successful in changing the attitude towards misusing prescription stimulants to: 1) Concentrate better while studying; 2) Study longer; and 3) Concentrate better in class (LaBelle et al., 2020). This implies that the media campaign successfully encouraged students to have better self-efficacy and controllability in their academic life.

\section{Conceptual Framework}

The researcher enhanced the existing model taking into consideration the significant influence of social media campaigns. This research updates the model of (Ajzen, 2006), as shown in Figure 2. Social media (SM) is a moderating variable between attitude (ATT), subjective norms (SN), self-efficacy (SE), controllability (CONT), and adherence to quarantine protocols (ATQP).

\section{Hypothesis 1:}

H1. Metro Manila residents with a positive attitude (ATT) towards the enhanced community quarantine or ECQ will adhere to quarantine protocols (ATQP) to prevent the spread of COVID-19.

Hypothesis 2:

H2. Metro Manila residents with a positive subjective norm (SN) towards adherence to quarantine protocols will adhere to quarantine protocols (ATQP) to prevent the spread of COVID-19.

Hypothesis 3:

H3. Metro Manila residents with greater self-efficacy (SE) towards adherence 


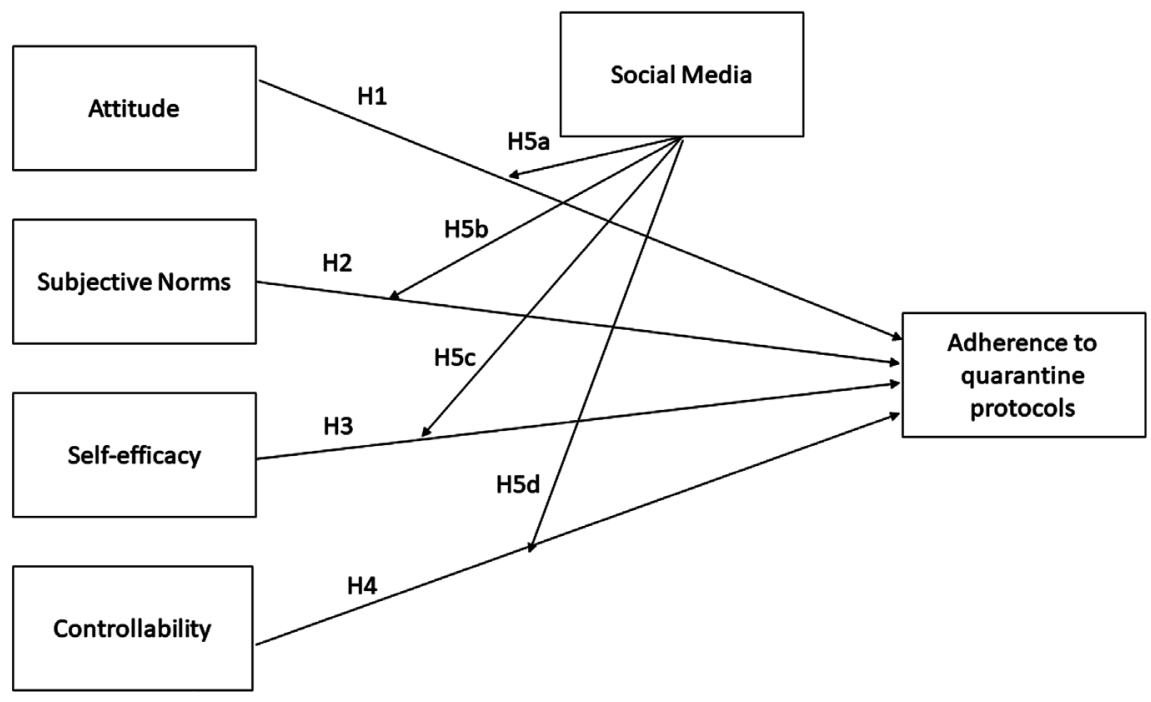

Figure 2. Conceptual model of adherence to quarantine protocols: the moderating effect of media.

to quarantine protocols (ATQP) will adhere to quarantine protocols to prevent the spread of COVID-19.

Hypothesis 4:

H4. Metro Manila residents with more controllability (CONT) towards adherence to quarantine protocols (ATQP) will adhere to quarantine protocols to prevent the spread of COVID-19.

Hypothesis 5:

H5a. Social media (SM) significantly moderates the relationship between attitude (ATT) of Metro Manila residents towards quarantine adherence and adherence to quarantine protocols (ATQP).

H5b. Social media (SM) significantly moderates the relationship between subjective norms (SN) and adherence to quarantine protocols (ATQP) of Metro Manila residents.

H5c. Social media (SM) significantly moderates the relationship between the self-efficacy (SE) of Metro Manila residents and adherence to quarantine protocols (ATQP).

H5d. Social media (SM) significantly moderates the relationship between the controllability (CONT) of Metro Manila residents and adherence to quarantine protocols (ATQP).

\section{Methodology}

This study used a causal research design. It explains the precise relationships between dimensions or characteristics of a phenomenon or differences between groups. Causal research uses current and previous data to forecast activity, behavior, and trends. This is to assess the impact as regards the specific changes on existing norms and various processes. Primary data from the study came from the online survey. Secondary data to support findings in the survey came from 
published manuscripts and similar studies. The researcher utilized convenience sampling and received a total of 413 survey responses administered via an online survey. There were 196 female and 217 male respondents. The respondents showed that $16 \%$ were students, while $84 \%$ were employed. The online survey was administered from August 15 to September 20, 2020, dates when the enhanced community quarantine (ECQ) and general community quarantine (GCQ) were implemented. The questionnaire had seven sections covering attitude, subjective norm, self-efficacy, controllability, and actual behavior.

Each section measured the participants' perceptions based on the Likert five-point scale (1-Strongly disagree, 2-Disagree, 3-Neutral, 4-Agree, and 5-Strongly agree). The participants were also requested to fill out the section on demographic profiles. The survey strategy allows the researcher to collect data that can be analyzed quantitatively via Partial Least Square-Structural Equation Modeling "PLS-SEM". Also, data collected can be used to suggest possible reasons for particular relationships between variables measured and latent constructs (Hair, Hult, Ringle, \& Sarstedt, 2011; Hair, Wolfinbarger Celsi, et al., 2011). Some questions were adopted from the 'Handbook of Marketing Scales" (Bearden \& Netemeyer, 1999). To test the validity of the questionnaires, the researcher conducted a pre-trial survey noting the respondents' comments and including the Cronbach's alpha for each variable.

\section{Results and Discussion}

It is shown in Table 1 that the number of male respondents (217) was greater than that of females (196). Indeed, 100\% of the survey participants were aged 21 to 40 years old. Moreover, $69 \%$ of them obtained a college degree. In terms of monthly income, $69 \%$ declared income between 21,000 to 30,000 Php.

\subsection{Evaluation of the Measurement Model and Discriminant Validity Assessment}

The conceptual framework, illustrated in Figure 2, shows an extended model of the Theory of Planned Behavior. The goal is to show the role of social media (SM) as a moderating variable of attitude (ATT), social norm (SN), self-efficacy (SC), and controllability (CONT). In this paper, the constructs are considered non-reflective because the composite reliability is not interchangeable. The discriminant validity assessment aims to ensure that the reflective construct will have the most robust relationships with its indicators (e.g., comparison with other constructs) in the PLS model (Hair et al., 2017). This assessment is a commonly accepted prerequisite for evaluating relationships among latent variables (Hair et al., 2017).

Table 2 shows the Heterotrait-Monotrait Ratio of correlations (HTMT), a method for assessing discriminant validity, one of the foundations of model evaluation. The researcher cannot affirm that the results hypothesized and the structural paths are accurate if discriminant validity is not manifested. Table 2 also shows the assessment of the constructs' discriminant validity. This establishes 
Table 1. Socio-demographic profile of respondents.

\begin{tabular}{|c|c|c|c|}
\hline Questions & Answers & Frequency & Percen \\
\hline \multirow{3}{*}{ Gender and Age } & Male & 217 & $52 \%$ \\
\hline & Female & 196 & $48 \%$ \\
\hline & $21-40$ & & \\
\hline \multirow{2}{*}{ Occupation } & Student & 65 & $16 \%$ \\
\hline & Employee & 347 & $84 \%$ \\
\hline \multirow{3}{*}{ Monthly Income } & Below 20,000 Php & 125 & $30 \%$ \\
\hline & $21,000-30,000 \mathrm{Php}$ & 283 & $69 \%$ \\
\hline & $31,000-50,000 \mathrm{Php}$ & 4 & $1 \%$ \\
\hline \multirow{4}{*}{$\begin{array}{l}\text { Educational } \\
\text { Attainment }\end{array}$} & College level & 65 & $16 \%$ \\
\hline & College graduate & 287 & $69 \%$ \\
\hline & Master's degree & 57 & $13 \%$ \\
\hline & Doctorate degree & 3 & $1 \%$ \\
\hline \multirow{3}{*}{$\begin{array}{l}\text { No. of hours spent on } \\
\text { social media }\end{array}$} & $2-3$ hours & 23 & $5 \%$ \\
\hline & 4 - 7 hours & 335 & $81 \%$ \\
\hline & More than 8 hours & 54 & $13 \%$ \\
\hline \multirow{4}{*}{ Purpose } & Connect with family and friends & 123 & $30 \%$ \\
\hline & News and information & 234 & $58 \%$ \\
\hline & Work from home & 177 & $43 \%$ \\
\hline & Online classes & 99 & $24 \%$ \\
\hline \multirow{5}{*}{ Connection Type } & Mobile data prepaid & 163 & $39 \%$ \\
\hline & Mobile data postpaid & 76 & $18 \%$ \\
\hline & Wireless postpaid broadband & 72 & $17 \%$ \\
\hline & DSL & 32 & $8 \%$ \\
\hline & Fiber & 29 & $7 \%$ \\
\hline
\end{tabular}

Table 2. Heterotrait-monotrait ratio (HTMT).

\begin{tabular}{cccccccccc}
\hline & AQTP & ATT & ATTXSM & CONT & CONTXSM & SM & SE & SEXSM & SN \\
\hline AQTP & & & & & & & & & \\
ATT & 0.807 & & & & & & & & \\
ATTXSM & 0.820 & 0.705 & & & & & & & \\
CONT & 0.820 & 0.717 & 0.699 & & & & & & \\
CONTXSM & 0.827 & 0.739 & 0.927 & 0.746 & & & & & \\
SM & 0.722 & 0.595 & 0.556 & 0.635 & 0.575 & & & & \\
SE & 0.809 & 0.686 & 0.700 & 0.913 & 0.713 & 0.677 & & & \\
SEXSM & 0.810 & 0.748 & 0.936 & 0.721 & 0.975 & 0.570 & 0.727 & & \\
SN & 0.745 & 0.725 & 0.651 & 0.695 & 0.644 & 0.618 & 0.746 & 0.652 & \\
SNXSM & 0.811 & 0.762 & 0.954 & 0.713 & 0.910 & 0.561 & 0.714 & 0.927 & 0.670 \\
\hline
\end{tabular}


that all the variables used in the study are statistically different from one another.

If the HTMT value is below 0.90 , the discriminant validity has been established between the two reflective constructs.

\subsection{Evaluation of the Structural Model}

Upon validating the constructs, the researcher assessed the structural model's predictive capabilities using social media. Table 3 shows the Cronbach's alpha to ensure scale reliability and consistency (Cronbach, 1951). According to Peterson (1994), a sufficient Cronbach alpha value is at least 0.70. Table 3 also shows that the constructs manifest internal consistency because it was all higher than 0.70 (Ketchen, 2013).

Cronbach's alpha is a measure of internal consistency and how closely related a set of items are as a group. It is considered to be a measure of scale reliability (Bruin, 2006). The alpha coefficient for the four variables is above 0.80 , which indicates that items have relatively high internal consistency. A reliability coefficient of 0.70 or higher is considered "acceptable" in most social science research. Spearman's rank correlation coefficient, or Spearman's rho_A, named after Charles Spearman, is a nonparametric measure of rank correlation. In the SEM context, rho_A must be above 0.70 (Bruin, 2006). The cut-off score for composite reliability is generally considered 0.70 (Nunnally, 1978). For convergent validity, the average variance extracted (AVE) score was used as a metric. An AVE score of more than 0.5 reflects good convergent validity (Bruin, 2006).

As shown in Figure 3, the original sample estimate is the parameter from model estimation on the original dataset from a standard PLS algorithm estimation. The sample mean estimate is the average of the estimates from all the subsamples of the dataset tabulated during the bootstrapping procedure. The signs in each bootstrap sample's measurement and structural models are made consistent with the signs in the original sample (Hair et al., 2017).

Table 4 presents the results through bootstrapping analysis using SMART-PLS. The researcher turned to basic statistical principles in interpreting the results: if

Table 3. Reliabilities, convergent and discriminant validities, and correlations among latent constructs of the measurement model.

\begin{tabular}{ccccc}
\hline Latent Constructs & $\begin{array}{c}\text { Cronbach's } \\
\text { Alpha }\end{array}$ & rho_A & $\begin{array}{c}\text { Composite } \\
\text { Reliability }\end{array}$ & $\begin{array}{c}\text { Average Variance } \\
\text { Extracted (AVE) }\end{array}$ \\
\hline ATQP & 0.950 & 0.951 & 0.960 & 0.801 \\
ATT & 0.943 & 0.950 & 0.959 & 0.855 \\
CONT & 0.982 & 0.982 & 0.985 & 0.916 \\
SM & 0.932 & 0.937 & 0.952 & 0.832 \\
SE & 0.948 & 0.948 & 0.962 & 0.865 \\
SN & 0.966 & 0.966 & 0.975 & 0.906 \\
\hline
\end{tabular}




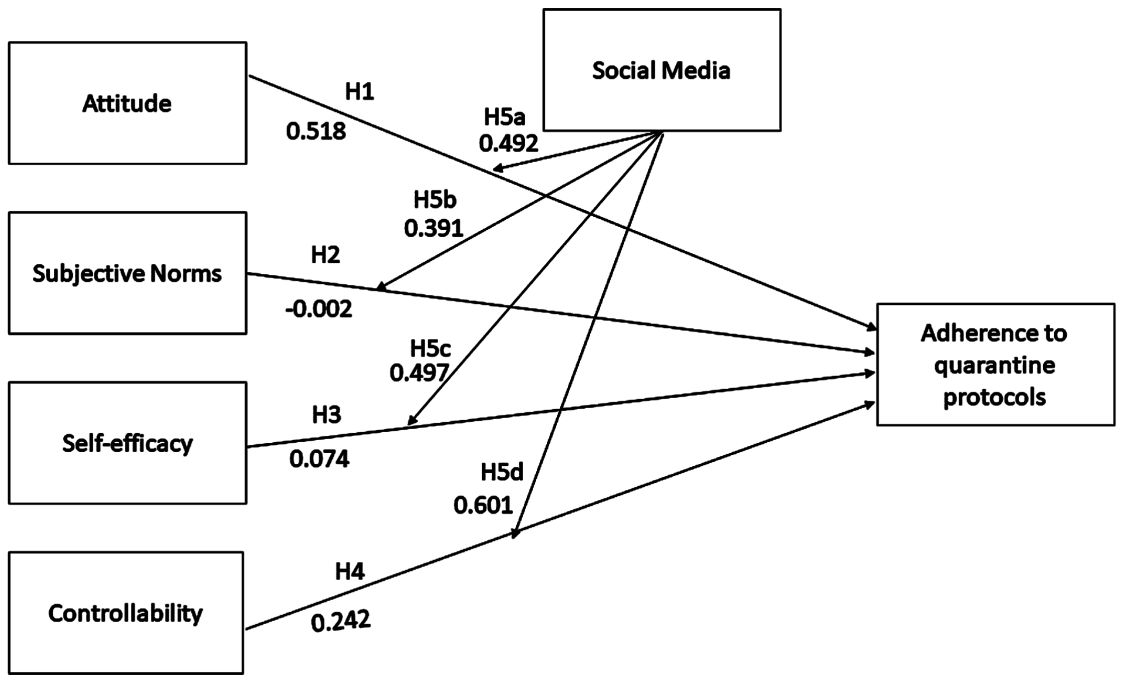

Figure 3. Conceptual model of adherence to quarantine protocols (Original samples).

the $\mathrm{P}$-value is less than 0.01 (very small), the results are considered highly significant, and if the P-value is greater (but not close to) 0.05 , the results are considered non-significant (Rumsey, 2010). It also summarizes the direct paths. The significant paths are attitude to adherence to quarantine protocols and controllability to adherence to quarantine protocols. Results showed that attitude is a consistent predictor for the two variables-social media and adherence to quarantine protocols. Social media positively affects attitude, social norms, self-efficacy, and controllability. This highlights the importance of developing the right attitude of the people to convince them to follow the quarantine guidelines.

Table 4 showed that the following hypotheses are supported: H1, H4, H4b, H5a, H5b, H5c, and H5d. On the other hand, these hypotheses were not supported: $\mathrm{H} 2$ and $\mathrm{H} 3$.

\subsection{Indirect Effect Paths}

The moderating effect of social media was further analyzed using the indirect effect paths. Table 5 also shows that social media moderates the relationship of attitude and adherence to quarantine protocols and controllability and adherence to quarantine protocols. This suggests that residents abide by the quarantine protocols with a positive attitude, and recognizing the dangers of violating the protocols can put one in danger of contracting COVID-19. COVID-19 and its consequences have led to fears, worries, and anxiety among individuals worldwide (Ahorsu et al., 2020). Adherence to quarantine protocols is a logical choice to minimize personal worries and preserve one's health. On the other hand, social media does not moderate social norms and self-efficacy to adherence, suggesting that getting praise or approval from other people is immaterial to adhering to quarantine protocols.

The results show that attitude was significant to adherence to quarantine protocols. This supports existing literature that attitude predicts actual behavior (Agarwal, 2014; Mo et al., 2019; Omodior et al., 2015; Schmid et al., 2017; Yang, 2015). 
Table 4. Hypothesis test results.

\begin{tabular}{ccccccc}
\hline & Path & $\begin{array}{c}\text { Original } \\
\text { Sample (0) }\end{array}$ & $\begin{array}{c}\text { Sample } \\
\text { Mean (M) }\end{array}$ & $\begin{array}{c}\text { Standard } \\
\text { Deviation (STDEV) }\end{array}$ & $\begin{array}{c}\text { T } \\
\text { Statistics }\end{array}$ & $\begin{array}{c}\text { P } \\
\text { Values }\end{array}$ \\
\hline H1 & ATT $\rightarrow$ ATQP & 0.518 & 0.482 & 0.110 & 4.695 & 0.000 \\
H2 & SN $\rightarrow$ ATQP & -0.002 & -0.001 & 0.026 & 0.083 & 0.934 \\
$\mathrm{H} 3$ & $\mathrm{SE} \rightarrow$ ATQP & 0.074 & 0.072 & 0.045 & 1.650 & 0.100 \\
$\mathrm{H} 4$ & $\mathrm{CONT} \rightarrow \mathrm{ATQP}$ & 0.242 & 0.248 & 0.064 & 3.789 & 0.000 \\
$\mathrm{H} 5 \mathrm{a}$ & $\mathrm{SM} \rightarrow \mathrm{ATT}$ & 0.492 & 0.458 & 0.127 & 3.870 & 0.000 \\
$\mathrm{H} 5 \mathrm{~b}$ & $\mathrm{SM} \rightarrow \mathrm{SN}$ & 0.391 & 0.376 & 0.108 & 3.633 & 0.000 \\
$\mathrm{H} 5 \mathrm{c}$ & $\mathrm{SM} \rightarrow \mathrm{SE}$ & 0.497 & 0.472 & 0.112 & 4.425 & 0.000 \\
$\mathrm{H} 5 \mathrm{~d}$ & $\mathrm{SM} \rightarrow \mathrm{CONT}$ & 0.601 & 0.587 & 0.084 & 7.146 & 0.000 \\
\hline$* \mathrm{p}<0.01$. & & & & & &
\end{tabular}

Table 5. Special indirect effects.

\begin{tabular}{cccccc}
\hline & $\begin{array}{c}\text { Original } \\
\text { Sample } \\
(\mathrm{O})\end{array}$ & $\begin{array}{c}\text { Sample } \\
\text { Mean } \\
(\mathrm{M})\end{array}$ & $\begin{array}{c}\text { Standard } \\
\text { Deviation } \\
(\mathrm{STDEV})\end{array}$ & $\begin{array}{c}\text { T Statistics } \\
(|\mathrm{O} / \mathrm{STDEV}|)\end{array}$ & $\begin{array}{c}\mathbf{P} \\
\text { Values }\end{array}$ \\
\hline $\mathrm{SM} \rightarrow \mathrm{ATT} \rightarrow \mathrm{ATQP}$ & 0.255 & 0.233 & 0.099 & 2.570 & $\mathbf{0 . 0 1 0}$ \\
$\mathrm{SM} \rightarrow \mathrm{CONT} \rightarrow \mathrm{ATQP}$ & 0.146 & 0.146 & 0.043 & 3.385 & $\mathbf{0 . 0 0 1}$ \\
$\mathrm{SM} \rightarrow \mathrm{SE} \rightarrow \mathrm{ATQP}$ & 0.037 & 0.034 & 0.025 & 1.481 & $\mathbf{0 . 1 3 9}$ \\
$\mathrm{SM} \rightarrow \mathrm{SN} \rightarrow \mathrm{ATQP}$ & -0.001 & 0.000 & 0.010 & 0.088 & $\mathbf{0 . 9 3 0}$ \\
\hline
\end{tabular}

The relationships between attitude and social media were statistically significant. This implies that beliefs, such as beliefs in quarantine protocols to stay alive, reward good health. This can enable a person to manage fear and worries brought by COVID 19 (Ahorsu et al., 2020; Biana \& Joaquin, 2020). The gradual lifting of ECQ to GCQ allows more movement, motivating Metro Manila residents to comply with the quarantine protocols (Sy et al., 2020; Torneo et al., 2020). The subjective norm was insignificant. This implies that an individual abides for personal reasons to stay alive and not because of pressure (Chan et al., 2009; Deci \& Ryan, 1985). Self-efficacy was not significant to quarantine protocols adherence. This implies that personal belief in the value of well-being is necessary to survive.

\section{Conclusion}

Social media is a powerful platform to encourage good health behaviors during the pandemic. The positive relationship between social media and adherence to quarantine protocols implies the crucial role of media in preventing the spread of COVID-19. Due to the stress caused by the type and exposure to social media during this time, it is suggested that responsible social media campaigns should use medical practitioners to guide the public on the benefits of quarantine adherence. Studies show that medical practitioners are credible influencers to health 
promotion behaviors (Bilal et al., 2020; Lep et al., 2020). The attitude was significant to adherence to quarantine protocols based on the study's results. This validates the existing literature that attitude is a predictor of actual behavior (Agarwal, 2014; Mo et al., 2019; Omodior et al., 2015; Schmid et al., 2017; Yang, 2015). Controllability was significant to adherence to quarantine protocols. This implies that residents can comply with quarantine protocols and favorable conditions for this health behavior compliance. The significance of social media to adherence to quarantine protocols points to the critical role of media in health behavior compliance, especially during COVID-19. The platform made people aware of what is happening locally and internationally. It allows them to have a positive attitude to stay alive and have a strong belief that well-being is essential. The results show that subjective norm and self-efficacy were not significant to adherence to quarantine protocols. This suggests that residents comply with quarantine protocols, not because of external pressures from family, peers, and the community, but rather because of their reason to stay alive. Social media moderated the relationship between attitude and quarantine protocols adherence. This suggests that social media can encourage favorable attitudes towards quarantine protocols adherence. This implies that social media can promote the resident's capability to comply with quarantine protocols. The moderating effect between controllability and quarantine protocols adherence also suggests that social media can create facilitating conditions for the residents to comply with quarantine adherence. Social media content that highlights the benefits of quarantine adherence can prevent the spread of COVID-19, especially when the vaccine is not yet available.

\section{Managerial Implications}

The worldwide pandemic has escalated, affecting pre-existing trends and introduced new challenges as we find our way to the new normal. The business and marketing implication talks about the influence of social media in the blurring picture of work and life balance. Distractions proliferate, and consumers are exposed to different content. It can be noted that people nowadays are very particular with health and safety protocols that for them to visit a place, specific measures must be established. Marketers and Entrepreneurs may benefit from this study by analyzing their social media marketing narrative and positioning products that promote compliance or adherence to safety and health protocols.

\section{Study's Limitation and Areas for Future Research}

Since the research was delimited to residents of Metro Manila, the findings of this study may not apply to other places in the country. Future research may check for provincial and regional differences in the relationship between the TPB antecedents, the effect of social media, and the intention to adhere to quarantine protocols. Moreover, most of the respondents were males. Future researchers can use an equal number of males and females to avoid gender bias. Future re- 
search can also test the framing of messages or advertising narrative and its effect on businesses, including the reception of the communication message and the consequent intention of individuals to adhere to quarantine protocols. Future studies related to the manuscript may also include the impact of COVID-19 on Gen Z. and Gen Y., including the emerging trends in communication and business brought by the pandemic.

\section{Conflicts of Interest}

The author declares no conflicts of interest regarding the publication of this paper.

\section{References}

Agarwal, V. (2014). A/H1N1 Vaccine Intentions in College Students: An Application of the Theory of Planned Behavior. Journal of American College Health, 62, 416-424. https://doi.org/10.1080/07448481.2014.917650

Ahorsu, D. K., Lin, C., Imani, V., Saffari, M., Griffiths, M., \& Pakpour, A. (2020). The Fear of COVID-19 Scale: Development and Initial Validation. International Journal of Mental Health and Addiction, 1-9. https://doi.org/10.1007/s11469-020-00270-8

Ajzen, I. (2006). Constructing a TPB Questionnaire: Conceptual and Methodological Considerations. http://people.umass.edu/aizen/tpb.html

Ay, P., Teker, A. G., Hidiroglu, S., Tepel, P., Surmen, A., Sili, U., Korten, V., \& Karavus, M. (2019). A Qualitative Study of Hand Hygiene Compliance among Health Care Workers in Intensive Care Units. The Journal of Infection in Developing Countries, 13, 111-117. https://doi.org/10.3855/jidc.10926

Bearden, W. O., \& Netemayer, R. G. (1999). Handbook of Marketing Scales (3rd ed.). Sage Publications. https://doi.org/10.4135/9781452224923

Biana, H., \& Joaquin, J. J. (2020). The Ethics of Scare: COVID-19 and the Philippines' Fear Appeals. Public Health, 183, 2-3. https://doi.org/10.1016/j.puhe.2020.04.017

Bilal, F. L., Bashirc, M., Komald, B., \& Tana, D. (2020). Role of Electronic Media in Mitigating the Psychological Impacts of Novel Coronavirus (COVID-19). Psychiatry Research, 289, Article ID: 113041. https://doi.org/10.1016/j.psychres.2020.113041

Boyd, D., \& Ellison, N. (2008). Social Network Sites: Definition, History, and Scholarship. Journal of Computer-Mediated Communication, 13, 210-230. https://doi.org/10.1111/j.1083-6101.2007.00393.x

Bruin, J. (2006). Newest: Command to Compute New Test. UCLA: Statistical Consulting Group. https://stats.idre.ucla.edu/stata/ado/analysis

Chan, G., Barnes-Holmes, D., Barnes-Holmes, Y., \& Stewart, I. (2009). Implicit Attitudes to Work and Leisure among North American and Irish Individuals: A Preliminary Study. International Journal of Psychology and Psychological Science, 9, 317-334.

CNN Health (2021) Tracking Coronavirus' Global Spread. https://edition.cnn.com/interactive/2020/health/coronavirus-maps-and-cases/

Cronbach, L. J. (1951). Coefficient Alpha and the Internal Structure of Tests. Psychometrika, 16, 297-334. https://doi.org/10.1007/BF02310555

Deci, E. L., \& Ryan, R. M. (1985). Intrinsic Motivation and Self-Determination in Human Behavior. Plenum Publishing. https://doi.org/10.1007/978-1-4899-2271-7

Duggan, A., \& Street, R. L. Jr. (2015). Interpersonal Communication in Health and Ill- 
ness. In K. Glanz, B. K. Rimer, \& K. V. Viswanath (Eds.), Health Behavior: Theory, Research, and Practice (pp. 243-267). Jossey-Bass/Wiley.

Garfin, D. R., Silver, R. C., \& Holman, E. A. (2020). The Novel Coronavirus (COVID-2019) Outbreak: Amplification of Public Health Consequences by Media Exposure. Health Psychology, 39, 355-357. https://doi.org/10.1037/hea0000875

Hair Jr., J. F., Hollingsworth, C. L., Randolph, A. B., \& Chong, A. Y. L (2017). An Updated and Expanded Assessment of PLS-SEM in Information Systems Research. Industrial Management \& Data Systems, 117, 442-458. https://doi.org/10.1108/IMDS-04-2016-0130

Hair Jr., J. F., Hult, G. T. M., Ringle, C. M., \& Sarstedt, M. (2011). A Primer on Partial Least Squares Structural Equation Modeling (PLS-SEM) (2nd ed.). Sage.

Hair, Jr. J. F., Wolfinbarger Celsi, M., Money, A. H., Samouel, P., \& Page, M. J. (2011). Essentials of Business Research Methods. Sharpe.

Hlavac, R. P. (2017). Social Media Marketing MOOC. Coursera Marketing. https://www.coursera.org/specializations/social-media-marketing

Ketchen, D. J. (2013). A Primer on Partial Least Squares Structural Equation Modeling. Long Range Planning, 46, 184-185. https://doi.org/10.1016/j.lrp.2013.01.002

Kotler, P., \& Keller, K. L. (2018). Marketing Management. Pearson Prentice Hall.

LaBelle, S., Ball, H., Weber, K., White, A., \& Hendry, A. (2020). The Rethink Campaign to Reduce the Normalization of Prescription Stimulant Misuse on College Campuses. Communication Quarterly, 68, 1-28. https://doi.org/10.1080/01463373.2019.1668446

Lep, Z., Babnik, K., \& Beyazoglu, K. H. (2020). Emotional Responses and Self-Protective Behavior within Days of the COVID-19 Outbreak: The Promoting Role of Information Credibility. Frontiers in Psychology, 11, 1846. https://doi.org/10.3389/fpsyg.2020.01846

Lovejoy, J., Riffe, D., \& Lovejoy, T. I. (2015). An Examination of Direct and Indirect Effects of Exposure and Attention to Health Media on Intentions to Avoid Unprotected Sun Exposure. Health Communication, 30, 261-270.

https://doi.org/10.1080/10410236.2013.842526

Mo, P. K. H., Lau, J. T. F., Xin, M., \& Fong, V. W. I. (2019). Understanding the Barriers and Factors to HIV Testing Intention of Women Engaging in Compensated Dating in Hong Kong: The Application of the Extended Theory of Planned Behavior. PLOS ONE, 14, e0213920. https://doi.org/10.1371/journal.pone.0213920

Namkoong, K., Nah, S., Record, R. A., \& Van Steed, S. K. (2017). Communication, Reasoning, and Planned Behaviors: Unveiling the Effect of Interactive Communication in an Anti-Smoking Social Media Campaign. Health Communication, 32, 41-50. https://doi.org/10.1080/10410236.2015.1099501

Nicomedes, C. J., \& Avila, R. M. (2020). An Analysis of the Panic during the COVID-19 Pandemic through an Online Form. Journal of Affective Disorders, 276, 14-22. https://doi.org/10.1016/j.jad.2020.06.046

Nunnally, J. C. (1978). Psychometric Theory(2nd ed.). McGraw-Hill.

Omodior, O., Pennington-Gray, L., \& Donohoe, H. (2015). Efficacy of the Theory of Planned Behavior in Predicting the Intention to Engage in Tick-Borne Disease Personal Protective Behavior Amongst Visitors to an Outdoor Recreational Center. Journal of Park and Recreation Administration, 33, 37-53.

Peterson, R. (1994). A Meta-Analysis of Cronbach's Coefficient Alpha. Journal of Consumer Research, 21, 381-391. https://doi.org/10.1086/209405

Prasetyo, Y. T., Castillo, A. M., Salonga, L. J., Sia, J. A., \& Senta, J. A. (2020). Factors Affecting Perceived Effectiveness of COVID-19 Prevention Measures among Filipinos 
during Enhanced Community Quarantine in Luzon, Philippines: Integrating Protection Motivation Theory and Extended Theory of Planned Behavior. International Journal of Infectious Diseases, 99, 312-323. https://doi.org/10.1016/j.ijid.2020.07.074

Rumsey, D. J. (2010). Statistics Essentials for Dummies. J. Wiley and Sons Ltd.

Schmid, P., Rauber, D., Betsch, C., Lidolt, G., \& Denker, M.-L. (2017). Barriers of Influenza Vaccination Intention and Behavior-A Systematic Review of Influenza Vaccine Hesitancy, 2005-2016. PLoS ONE, 12, e0170550.

https://doi.org/10.1371/journal.pone.0170550

Stryker, E., Moriarty, C., \& Jensen, J. (2008) Effects of Newspaper Coverage on Public Knowledge about Modifiable Cancer Risks. Health Communication, 23, 380-390. https://doi.org/10.1080/10410230802229894

Sundstrom, B., Ferrara, M., DeMaria, A. L., Gabel, C., Booth, K., \& Cabot, J. (2018). It Is Your Place: Development and Evaluation of an Evidence-Based Bystander Intervention Campaign. Health Communication, 33, 1141-1150. https://doi.org/10.1080/10410236.2017.1333561

Sy, C., Bernardo, E., Miguel, A., San Juan, J. L. M., Andres, P., Mae Ching, P., Culaba, A., Ubando, A., \& Mutuc, J. E. (2020). Policy Development for COVID-19 Pandemic Response Using System Dynamics. https://doi.org/10.1007/s41660-020-00130-x https://www.dlsu.edu.ph/research/covid-19-research-portal\#pb

Torneo, A., Andres, A. A., Berse, K., Borja, R., Salvosa, F., \& Soriano, C. R. (2020). Setting up a COVID-19 Community Response Strategy in Local Government Units: Immediate, Transitory, and Medium-Term Considerations for Planning. Policy Brief, 1, 1. https://covid19arc.ph/research-think-pieces

Vallejo, B., \& Ong, R. A. (2020). Policy Responses and Government Science Advice for the COVID 19 Pandemic in the Philippines: January to April 2020. Progress in Disaster Science, 7, Article ID: 100115. https://doi.org/10.1016/j.pdisas.2020.100115

White, K. M., Jimmieson, N. L., Obst, P. L., Graves, N., Barnett, A., Cockshaw, W., Gee, P., Haneman, L., Page, K., Campbell, M., Martin, E., \& Paterson, D. (2015). Using the Theory of Planned Behavior Framework to Explore Hand Hygiene Beliefs at the "5 Critical Moments" among Australian Hospital-Based Nurses. BMC Health Services Research, 15, 59. https://doi.org/10.1186/s12913-015-0718-2

Yang, Z. J. (2015). Predicting Young Adults' Intentions to Get the H1N1 Vaccine: An Integrated Model. Journal of Health Communication, 20, 69-79. https://doi.org/10.1080/10810730.2014.904023 